\title{
Preparation of Polystyrene-Polyimide Particles by Dispersion Polymerization of Styrene Using Poly(amic acid) as a Stabilizer
}

\author{
Shinji Watanabe, ${ }^{\dagger}$ Kenji Ueno, Miki Murata, and Yuzuru Masuda \\ Department of Materials Science, Kitami Institute of Technology, Kitami 090-8507, Japan
}

(Received December 1, 2005; Accepted January 13, 2006; Published May 15, 2006)

\begin{abstract}
Dispersion polymerization of styrene (S) and a cationic comonomer, 4-(vinylbenzyl)trimethylammonium chloride (VBA) was conducted in alkaline aqueous ethanol using various aromatic poly(amic acid)s (PAA) as stabilizers. The monodisperse particles were obtained in high yield using the optimum composition of solvent mixture depending on the PAA structure. By using a cationic comonomer (VBA), PAA was incorporated quantitatively into the particles. On the other hand, using cationic methacrylates as a comonomer, PAA was not incorporated effectively. The imidization of PAA on the particles proceeded with acetic anhydride and 4-(dimethylamino)pyridine to form PS-polyimide (PS-PI) particles. The PS-PI particles were maintained in spherical shape by the thermal treatment up to $240^{\circ} \mathrm{C}$. PI hollow particles were also obtained by washing PS-PI particles with toluene. [doi:10.1295/polymj.38.471] KEY WORDS Dispersion Polymerization / Poly(amic acid) / Polyimide / Hollow Particle / Thermal Stability /
\end{abstract}

Dispersion polymerization is a versatile method for preparation of monodisperse polymer particles in the $0.5-10 \mu \mathrm{m}$ size range. Especially the polymerization of styrene and methyl methacrylate has been extensively studied in polar media. ${ }^{1}$ To disperse particles stably, a suitable steric stabilizer was used, such as polyethylene oxide, ${ }^{2}$ polyvinylpyrrolidone, ${ }^{3}$ poly(2ethyl-2-oxazoline), ${ }^{4}$ hydroxypropyl cellulose, ${ }^{5}$ and poly(acrylic acid). ${ }^{6}$

Aromatic polyimides (PI) are the most useful super engineering plastics which exhibit excellent thermal, electrical, and mechanical properties, and have been used widely in aerospace, electronics, and other industries. They are generally prepared through a two-step procedure by the ring-opening polyaddition of aromatic diamines to aromatic tetracarboxylic dianhydrides giving poly(amic acid)s (PAA), followed by thermal cyclodehydration. ${ }^{7,8}$ Since PAA has pendant carboxylic acids and is soluble in potassium carbonate aqueous ethanol solution, it would work as a steric stabilizer for dispersion polymerization. In the previous study, we shortly reported the dispersion polymerization of styrene (S) using an aromatic poly(amic acid) (PAA 2a) in an aqueous ethanol medium. ${ }^{9}$ After the polymerization, PAA was easily converted to polyimide to yield PS-PI particles (Scheme 1). Thus PAA would play two important roles, i.e., a steric stabilizer during polymerization, and improvement in mechanical and thermal properties of particles by means of imidization of PAA. For this purpose, PAA must be incorporated into the particles effectively. In general dispersion polymerization, most of steric stabilizer was not incorporated into the particles. To incorporate it into particles effectively, reactive stabilizers having polymerizable group ${ }^{10}$ or radical transfer agent (mercapto group $)^{11}$ were used in the polymerization and stabilized particles even in their low concentration because they reacted with monomer and incorporated into the particles. In this study, a cationic comonomer, 4-vinylbenzyltrimethylammonium chloride (VBA), was employed in the dispersion polymerization. VBA could copolymerize with $\mathrm{S}$ to form cationic particles,

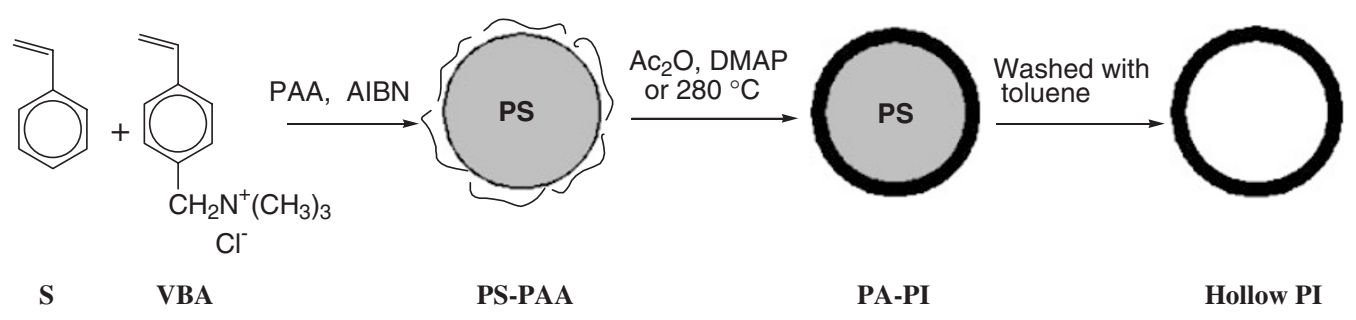

Scheme 1.

${ }^{\dagger}$ To whom correspondence should be addressed (Fax: +81-157-26-4973, E-mail: watash@mail.kitami-it.ac.jp). 


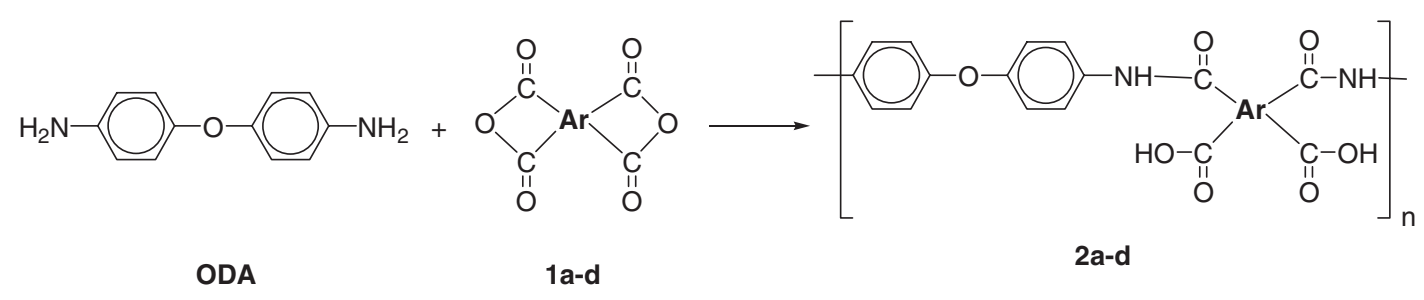

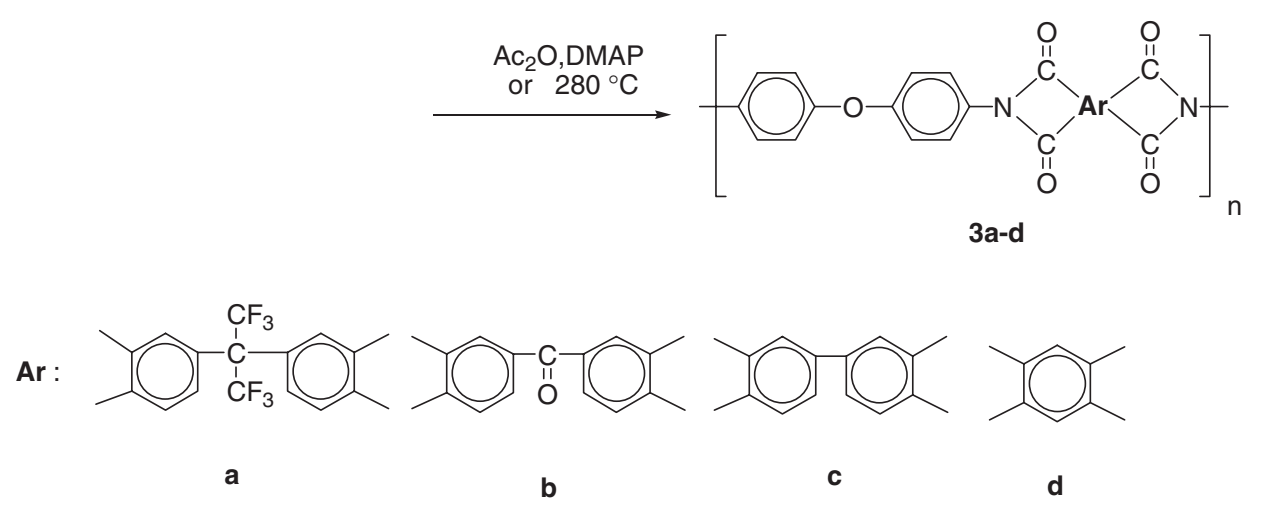

Scheme 2.

as a result, an anionic PAA could be adsorbed onto the particles by their electrostatic attraction. ${ }^{9}$

This article describes the various PAAs were employed as a steric stabilizer for dispersion polymerization and the preparation of PS-PI particles by dehydration of PAA on the particles.

\section{EXPERIMENTAL}

\section{Measurements}

Diameter of polymer particle was determined by a scanning electron microscope (JEOL JSM-588 scanning microscope). X-Ray photoelectron spectroscopic data were obtained on a RIGAKU XPS-7000 instrument with $\mathrm{Al} \mathrm{K} \alpha \mathrm{X}$-ray source $(10 \mathrm{kV}, 30 \mathrm{~mA})$ at a take-off angle of $90^{\circ}$.

\section{Materials}

$\mathrm{S}$ was washed with aqueous $\mathrm{NaOH}$ and distilled under reduced pressure. 2,2'-Azobisisobutyronitrile (AIBN) was recrystallized from methanol. Poly(amic acid) (PAA) was prepared by the conventional ringopening polyaddition of aromatic tetracarboxylic dianhydrides (1a-1d) with 4,4'-oxydianiline and purified by reprecipitation with water or methanol (Scheme 2). ${ }^{12}$ Their inherent viscosities in $N, N$-dimethylacetamide (DMAc) at $30^{\circ} \mathrm{C}$ were summarized in Table I. 4-Vinylbenzyltrimethylammonium chloride (VBA) was synthesized by the reaction of 4vinylbenzyl chloride with trimethylamine ${ }^{13}$ and recrystallized from a mixture of acetonitrile and acetone $(\mathrm{v} / \mathrm{v}=1 / 1)$. Other reagents were obtained commercially and used as received.
Table I. Synthesis of poly(amic acid) ${ }^{\mathrm{a}}$

\begin{tabular}{cc}
\hline \multirow{2}{*}{ PAA } & Viscosity $^{\mathrm{b}}$ \\
\cline { 2 - 2 } & $(\mathrm{dL} / \mathrm{g})$ \\
\hline $\mathbf{2 a}$ & 0.76 \\
$\mathbf{2 b}$ & 1.20 \\
$\mathbf{2 c}$ & 0.64 \\
$\mathbf{2 d}$ & 0.81 \\
\hline
\end{tabular}

${ }^{\mathrm{a}} \mathrm{ODA}(10 \mathrm{mmol})$ and tetracarboxylic dianhydrides $\mathbf{1 a}-\mathbf{1 d}$ $(10 \mathrm{mmol})$ were polymerized in $25 \mathrm{~mL}$ of DMAc at $12{ }^{\circ} \mathrm{C}$ for $1.5 \mathrm{~h}$ and at room temperature for $1 \mathrm{~h}$. ${ }^{\mathrm{b}}$ Inherent viscosity of 2a-2d was measured in $0.5 \mathrm{~g} / \mathrm{dL}$ of DMAc solution at $30^{\circ} \mathrm{C}$.

\section{Dispersion Polymerization}

Typical dispersion polymerization was conducted as follows. PAA 2a $(0.266 \mathrm{~g}$; monomer unit: 0.42 $\mathrm{mmol})$, VBA $(0.212 \mathrm{~g} ; 1.0 \mathrm{mmol})$, and potassium carbonate $(0.104 \mathrm{~g} ; 0.75 \mathrm{mmol})$ were dissolved in $100 \mathrm{~mL}$ of ethanol-water $(80 / 20=\mathrm{v} / \mathrm{v})$. Into the solution, $\mathrm{S}$ $(8.0 \mathrm{~g} ; 76.8 \mathrm{mmol})$ and AIBN $(0.16 \mathrm{~g} ; 1.0 \mathrm{mmol})$ were added. The mixture was purged with nitrogen and stirred at $70^{\circ} \mathrm{C}$ for $20 \mathrm{~h}$ with mechanical stirrer in nitrogen atmosphere. After removal of coagulated polymer by filtration, the resulting particles were purified with centrifugation using ethanol for three times.

\section{Fluorine Content of the Particles}

To determine the incorporation ratio of $2 \mathbf{a}$ into the particles, the fluorine content of the particles was measured by the lanthanum alizarin complexone method as described in ref 14 . Lyophilized polymer $(10 \mathrm{mg})$ wrapped with filter paper $(2 \mathrm{~cm} \times 2 \mathrm{~cm})$ was completely subjected to combustion under oxygen 
atmosphere in a combustion flask containing deionized water $(20 \mathrm{~mL})$. The evolved fluorine was absorbed into the water. Into the fluorine anion solution $(1.6 \mathrm{~mL}), 1 \mathrm{~mL}$ of $5 \%$ aqueous alfusone ${ }^{\circledR}$ solution (DOJINDO), $0.4 \mathrm{~mL}$ of $1.0 \mathrm{M}$ acetate buffer ( $\mathrm{pH} 5.0$ ), $2 \mathrm{~mL}$ of acetone, and $5 \mathrm{~mL}$ of deionized water were added and the solution was allowed to stand at room temperature for $1 \mathrm{~h}$. The absorption of solution was measured at $610 \mathrm{~nm}$.

\section{Imidization of PAA on the Polymer Particle}

Lyophilized polymer particles $(1.0 \mathrm{~g})$ were suspended in a solution of $2.0 \mathrm{~g}$ of 4-(dimethylamino)pyridine (DMAP) in $15 \mathrm{~mL}$ of acetic anhydride $\left(\mathrm{Ac}_{2} \mathrm{O}\right)$ and stirred at room temperature for $1 \mathrm{~d}$. The suspension was poured into $50 \mathrm{~mL}$ of water and the particles were centrifuged, washed with ethanol twice, and dried under reduced pressure. PS-PI particles were recovered quantitatively (98\%).

To separate the PI shell, the resulting particles were suspended in $30 \mathrm{~mL}$ of toluene and stirred at room temperature for $3 \mathrm{~h}$ and centrifuged with toluene twice.

\section{RESULTS AND DISCUSSION}

Dispersion polymerization of S and cationic comonomer, VBA was carried out using PAA (2a) as a steric stabilizer in an alkaline aqueous ethanol. ${ }^{15}$ Table II shows the results of polymerization changing the amounts of 2a and water. When more than $23 \mathrm{~mL}$ of water was added, the size distribution was a little

Table II. Dispersion polymerization of S using poly(amic acid) 2a as a stabilizer ${ }^{\mathrm{a}}$

\begin{tabular}{|c|c|c|c|c|c|c|c|}
\hline $\begin{array}{l}\text { Run } \\
\text { No. }\end{array}$ & $\begin{array}{c}\mathbf{2 a} \\
(\mathrm{mmol})\end{array}$ & $\begin{array}{l}\mathrm{H}_{2} \mathrm{O} \\
(\mathrm{mL})\end{array}$ & $\begin{array}{l}\text { Yield } \\
(\%)\end{array}$ & $\begin{array}{c}\text { Coagulated } \\
\text { Polymer }^{\mathrm{b}} \\
(\%)\end{array}$ & $\begin{array}{c}\text { Dn } \\
(\mu \mathrm{m})\end{array}$ & Dw/Dn & $\begin{array}{c}\text { Incorporated } \\
\text { PAA }^{\mathrm{c}} \\
(\%)\end{array}$ \\
\hline 1 & 0.42 & 30 & 80 & 0 & 0.90 & 1.04 & 100 \\
\hline 2 & 0.42 & 23 & 61 & 33 & 0.91 & 1.02 & 100 \\
\hline 3 & 0.42 & 20 & 87 & 0 & 0.74 & 1.01 & 97 \\
\hline $4^{\mathrm{d}}$ & 0.42 & 20 & 0 & 100 & $-^{\mathrm{f}}$ & $-^{f}$ & $-^{f}$ \\
\hline $5^{\mathrm{e}}$ & 0.42 & 20 & 64 & 18 & $-^{\mathrm{f}}$ & $-^{f}$ & 18 \\
\hline 6 & 0.42 & 15 & 51 & 32 & 0.64 & 1.01 & 100 \\
\hline 7 & 0.21 & 20 & 88 & 3 & 0.69 & 1.01 & 100 \\
\hline 8 & 0.62 & 20 & 78 & 12 & 0.91 & 1.01 & 97 \\
\hline 9 & 0.83 & 20 & 78 & 11 & 0.94 & 1.01 & 88 \\
\hline 10 & 1.25 & 20 & 0 & 100 & $-^{\mathrm{f}}$ & $-^{f}$ & $-^{\mathrm{f}}$ \\
\hline
\end{tabular}

as: $76.8 \mathrm{mmol}, \mathrm{AIBN}: 1.0 \mathrm{mmol},[\mathbf{2 a}] /[\mathrm{VBA}] /\left[\mathrm{K}_{2} \mathrm{CO}_{3}\right]=$ $1.0 / 2.4 / 1.8$, solvent $\left(\mathrm{H}_{2} \mathrm{O}+\mathrm{EtOH}\right): 100 \mathrm{~mL}, 70^{\circ} \mathrm{C}, 24 \mathrm{~h}$. ${ }^{\mathrm{b}}$ Yield of coagulated polymer during polymerization. ${ }^{\mathrm{c}}$ Ratio of incorporated PAA determined by fluorine content of the particle. ${ }^{\mathrm{d}}$ 2-Dimethylaminoethyl methacrylate was used as a cationic comonomer. ${ }^{\mathrm{e}}$ [2-(Methacryloyloxy)ethyl]trimethylammonium chloride was used as a cationic comonomer. ${ }^{\mathrm{f}} \mathrm{Not}$ analyzed. broader (run no. 1) or a coagulated polymer was afforded (run no. 2). The polymerization using a small amount of water $(15 \mathrm{~mL})$ also induced the coagulation of polymer (run no. 6). Using $20 \mathrm{~mL}$ of water, monodisperse particles were yielded quantitatively (run no. 3). Solvent composition is well known to play a key role in the particle size. Generally, an increase in solvent polarity leads to formation of smaller particles, because more nuclei are produced in more polar medium. On the other hand, Paine reported the polymerization of styrene in a series of alcohols with a varying polarity. The particle size showed a maximum when the solubility parameter of medium was closed that of stabilizer. ${ }^{3 b}$ In our case, the particle size increased with increasing amounts of water. Since the anionic PAA and cationic comonomer were used, nuclei formation must be complex.

The dispersion polymerization using less than $0.83 \mathrm{mmol}$ of $\mathbf{2 a}$, gave monodisperse polymer particles in high yield (run nos. 7-9). When $1.25 \mathrm{mmol}$ of 2a was used, all polymer was coagulated during the polymerization (run no. 10). To estimate the amount of 2a incorporated into the particles, the fluorine contents of particles were determined by the lanthanum alizarin complexone method. The particles were completely subjected to combustion and the evolved fluorine anion was detected by the lanthanum alizarin complexone reagent. Hence, all of the fluorine in the particles could be detected. Judging from the fluorine content of particles, most of 2a was immobilized into the particles. To incorporate PAA into the particles, a cationic comonomer (VBA) was necessary for the polymerization. ${ }^{9}$ Other cationic comonomers were also examined. When 2-dimethylaminoethyl methacrylate, a methacrylate having tertiary amine, was used, no polymer particle was yielded during the polymerization (run no. 4). Although the polymerization using 2-(methacryloyloxy)ethyl]trimethylammonium chloride (MEA) afforded the particles, only $18 \%$ of $2 \mathbf{a}$ were incorporated into the particles (run no. 5). VBA was copolymerized with $S$ to form the cationic particles and then PAA was incorporated into the particles by their electrostatic attraction. Furthermore, ionic VBA itself might make the particles dispersed stably in the polymerization media. Since MEA was hydrophilic compared with VBA, MEA might mainly be polymerized in the solution. Consequently PAA was not incorporated into the particles.

The initial styrene concentration is important for the final particles size because the particle number is determined in very early stage. In general, particle size increases with the monomer concentration. Figure 1 shows the particle diameter against the amount of $\mathrm{S}$ in feed. The particle size increased with the amount of $\mathrm{S}$ from $0.59 \mu \mathrm{m}$ to $1.5 \mu \mathrm{m}$. In all cases, 


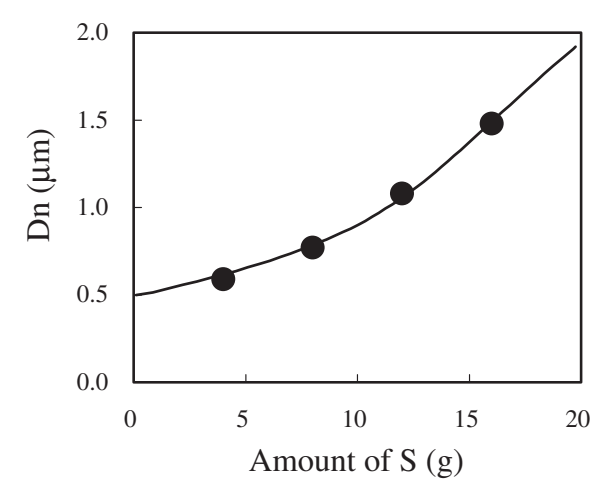

Figure 1. Effect of amount of $\mathrm{S}$ on particle size $(\mathbf{2 a}=0.42$ $\mathrm{mmol}, \mathrm{VBA}=1.0 \mathrm{mmol}, \mathrm{K}_{2} \mathrm{CO}_{3}=0.75 \mathrm{mmol}$, ethanol $=80$ $\mathrm{mL}$, and water $=20 \mathrm{~mL}$ ).

Table III. Dispersion polymerization using various poly(amic acid) $s^{a}$

\begin{tabular}{|c|c|c|c|c|c|c|}
\hline PAA & $\begin{array}{l}\mathrm{H}_{2} \mathrm{O} \\
(\mathrm{mL})\end{array}$ & $\begin{array}{c}\text { Yield } \\
(\%)\end{array}$ & $\begin{array}{c}\text { Coagulated } \\
\text { Polymer }^{\mathrm{b}} \\
(\%)\end{array}$ & $\begin{array}{c}\text { Dn } \\
(\mu \mathrm{m})\end{array}$ & $\mathrm{Dw} / \mathrm{Dn}$ & $\begin{array}{c}\text { Incorporated } \\
\text { PAA } \\
(\%)\end{array}$ \\
\hline $2 a$ & 20 & 80 & 0 & 0.74 & 1.01 & $96^{\mathrm{c}}$ \\
\hline $2 b$ & 20 & 52 & 38 & $-\mathrm{d}$ & $-\mathrm{d}$ & $-\mathrm{d}$ \\
\hline $2 b$ & 23 & 53 & 17 & 1.42 & 1.02 & $-^{\mathrm{d}}$ \\
\hline $2 b$ & 30 & 83 & 5 & 1.20 & 1.02 & $90^{\mathrm{e}}$ \\
\hline $2 c$ & 20 & 67 & 8 & 0.78 & 1.02 & $-^{\mathrm{d}}$ \\
\hline $2 c$ & 25 & 88 & 3 & 0.80 & 1.01 & $-^{\mathrm{d}}$ \\
\hline $2 c$ & 30 & 86 & 7 & 0.77 & 1.02 & $98^{\mathrm{e}}$ \\
\hline $2 d$ & 20 & 0 & 100 & $-^{\mathrm{d}}$ & $-^{\mathrm{d}}$ & $-^{\mathrm{d}}$ \\
\hline $2 d$ & 25 & 83 & 7 & 0.87 & 1.02 & $\simeq^{\mathrm{d}}$ \\
\hline $2 d$ & 30 & 83 & 7 & 1.10 & 1.01 & $-^{\mathrm{d}}$ \\
\hline
\end{tabular}

aPAA: $0.42 \mathrm{mmol}, \mathrm{S}: 8.0 \mathrm{~g}$, VBA: $1.0 \mathrm{mmol}$, AIBN: $0.16 \mathrm{~g}$, $\mathrm{K}_{2} \mathrm{CO}_{3}$ : $0.75 \mathrm{mmol}$, Solvent $\left(\mathrm{H}_{2} \mathrm{O}+\right.$ ethanol): $100 \mathrm{~mL}, 70^{\circ} \mathrm{C}$, $24 \mathrm{~h}$. ${ }^{\mathrm{b}}$ Yield of coagulated polymer during polymerization. ${ }^{\mathrm{c}}$ The incorporated PAA was determined by fluorine content. ${ }^{\mathrm{d}}$ Not analyzed. ${ }^{\mathrm{e}}$ The incorporated PAA was determined by the absorbance of supernatant after centrifugation at $295 \mathrm{~nm}$.

monodisperse particles immobilized with 2a (more than $88 \%$ ) were obtained.

PAA was known to be hydrolyzed in alkaline solution. PAA 2a was treated with the alkaline solution under the same condition as the polymerization in the absence of $\mathrm{S}$, and its inherent viscosity was measured. Although the inherent viscosity of 2a decreased 0.76 to $0.32 \mathrm{dL} / \mathrm{g}$, the PAA treated with alkaline solution had still moderate inherent viscosity. Since most PAA was incorporated onto the particles during the polymerization, hydrolysis of PAA did not occur considerably.

Based on the optimum polymerization condition using 2a, other PAAs (2b-2d) were employed as a stabilizer (Table III). Since $\mathbf{2 b - 2 d}$ were slightly soluble in alkaline aqueous ethanol at room temperature, the PAA solutions were heated to $50^{\circ} \mathrm{C}$ to dissolve them completely and the polymerizations were performed.
In case of $\mathbf{2 a}, 20 \mathrm{~mL}$ of water was the optimum solvent composition. However, the particles using the other PAAs tended to be coagulated during the polymerization in the same solvent composition. Especially the polymerization using $\mathbf{2 d}$ resulted in the coagulation of all the polymer particles. As volume of water increased to $30 \mathrm{~mL}$, the polymer particles having $\mathbf{2 b}-$ $\mathbf{2 d}$ were obtained in quantitative yields. Since the solubilities of $\mathbf{2 b}-\mathbf{2 d}$ were different from that of $\mathbf{2 a}$, the optimum solvent composition was also changed. The amount of $\mathbf{2 b}$ or $\mathbf{2 c}$ incorporated into the particles was measured by the absorption of supernatant after centrifugation and more than $90 \%$ of $\mathbf{2 b}$ and $\mathbf{2 c}$ were found to be incorporated into the particles.

The obtained particles were subjected to the subsequent heating at $60,80,100,150,250$, and $280^{\circ} \mathrm{C}$ for 30 min each in vacuo. PS particles without PAA were not kept in spherical shape by the thermal treatment because of the low $T_{\mathrm{g}}$ of PS $\left(100^{\circ} \mathrm{C}\right)$. On the other hand, the particles having PAA 2a were maintained in spherical shape with some voids even after the thermal treatment (Figure $2 \mathrm{~b}$ ). The more rapid rise of temperature i.e., at $60^{\circ} \mathrm{C}$ for $30 \mathrm{~min}$, at $100^{\circ} \mathrm{C}$ for $1 \mathrm{~h}$, at $200^{\circ} \mathrm{C}$ for $1 \mathrm{~h}$, and at $250^{\circ} \mathrm{C}$ for $1 \mathrm{~h}$ made the particles fused together. PAA was gradually converted into PI even at low temperature. If the conversion of PAA was inadequate, the particles started fusing above $100^{\circ} \mathrm{C}$. While more PAA was converted into PI by the slow temperature rise, PI 3a $\left(T_{\mathrm{g}}: 301{ }^{\circ} \mathrm{C}\right)$ shell protected the particles to maintain in the spherical shape even at high temperature.

The imidization of PAA on the particles (run no. 3) was also carried out using acetic anhydride and 4-(dimethylamino)pyridine at room temperature for $1 \mathrm{~d}$ and washed with ethanol. The fluorine content of particles was not changed after the imidization (before $274 \mu \mathrm{mol} / \mathrm{g}$, after $281 \mu \mathrm{mol} / \mathrm{g}$ ), meaning that no PI was desorbed from the particles. Although the particle size was not changed by the imidization, the particles were likely to be fused together, and some gel like materials existed on the surface (Figure 2c). Even after heating at $240^{\circ} \mathrm{C}$ for $2 \mathrm{~h}$ in vacuo, some PS-PI particles were kept in their spherical shapes.

The atomic ratio of fluorine to carbon of the PS-PI particles determined by XPS was $35.9 \times 10^{-3}$, which was much lager than that determined by the lanthanum alizarin complexone method $(\mathrm{F} / \mathrm{C}=3.56 \times$ $10^{-3}$ ). This means that PI was mainly located at the particles surface. During dispersion polymerization, hydrophilic PAA was localized on surface and hydrophobic PS was formed as a core polymer. Even if PI was formed by the dehydration of PAA, it would be still localized on the surface to yield core-shell PS-PI particles. Although PI content was only 2.8\% weight of the particles (run no. 3), PI shell kept the 


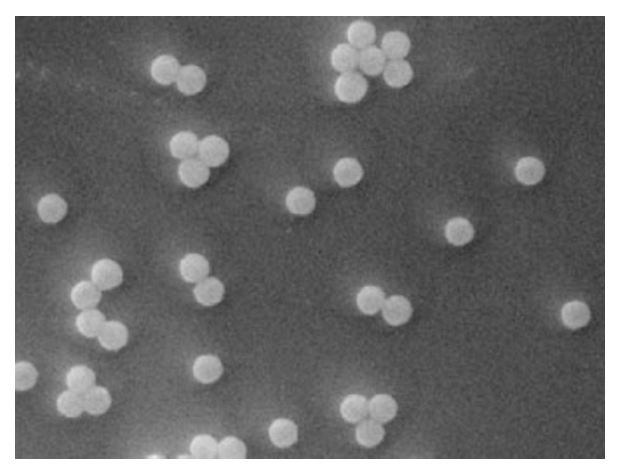

(a)

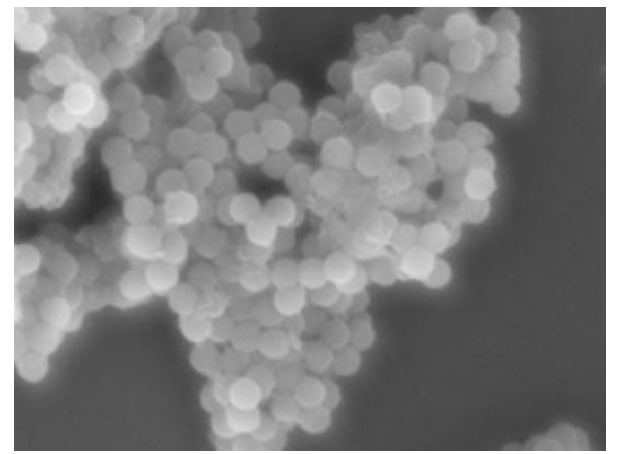

(c)

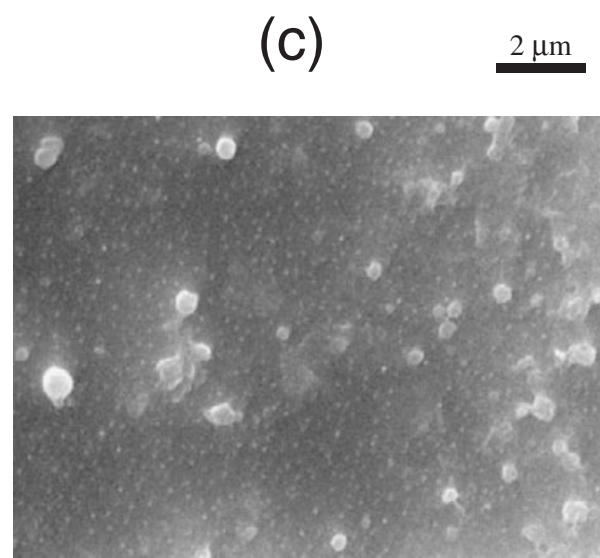

(e)

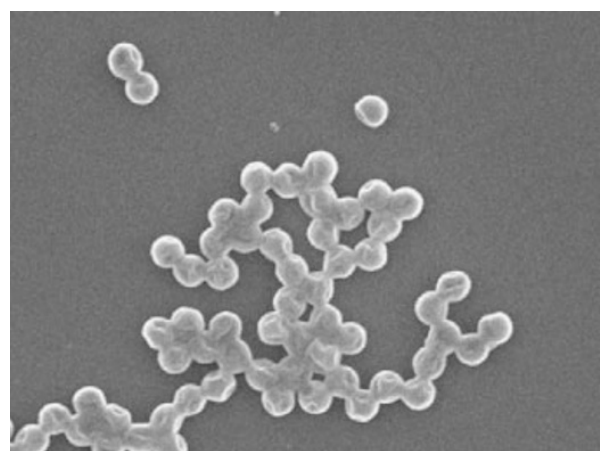

(b)

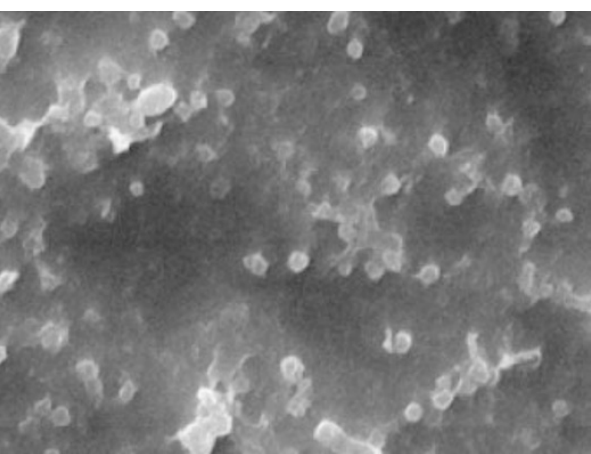

(d) $\quad \underline{2 \mu \mathrm{m}}$

Figure 2. Scanning electron spectra of (a) PS-PAA particles (run no. 3; see Table II) (b) PS-PI particles prepared by thermal treatment. (c) PS-PI particles prepared by chemical imidization. (d) PI particles. (e) PI particles after heating at $240{ }^{\circ} \mathrm{C}$ for $2 \mathrm{~h}$.

particle in spherical shape at $240{ }^{\circ} \mathrm{C}$.

PI hollow particles were prepared by extraction of the PS-PI particles with toluene. By FT-IR measurement, almost PS was removed and characteristic absorptions of PI was detected. ${ }^{9}$ PI particles were shrunk and changed in shape (Figure 2d). The polyimide chains must have stress by the cyclodehydration of PAA. By treating with toluene, core polystyrene was removed and PI swelled a little. As a result, the polyimide chains might be reoriented to release the chain stress. Assuming that PI was localized to the surface on the PS-PI particles, the PI thickness could be calculated from the diameter and PI content at about
$3.4 \mathrm{~nm}$. Although PI thickness was very thin and the hollow particles were purified by centrifugation i.e., the particles were subjected to the centrifugal force ( $21500 \mathrm{G})$, PI hollow particles were kept in the spherical shape mainly due to the excellent mechanical and thermal properties of polyimide. Furthermore they maintained in spherical shape even after heating to $240{ }^{\circ} \mathrm{C}$ in vacuo (Figure $2 \mathrm{e}$ ).

In conclusion, PS-PAA particles were prepared by the dispersion polymerization of styrene (S) and VBA using various aromatic poly(amic acid)s as stabilizers in an aqueous ethanol. The monodisperse particles were obtained in high yield using the optimum com- 
position of solvent mixture depending on the PAA structure. By using a cationic comonomer (VBA), PAA was incorporated quantitatively into the particles. The imidization of PAA on the particles proceeded with acetic anhydride and 4-(dimethylamino)pyridine to form PS-PI particles. The PS-PI particles were maintained in spherical shape by the thermal treatment up to $240^{\circ} \mathrm{C}$.

\section{REFERENCES}

1. For review K. Narayanan, N. Jayachandran, and P. R. Chatterji, J. Macromol. Sci., Polym. Rev., C41, 79 (2001).

2. a) P. Lacroix-Desmazes and A. Guyot, Macromolecules, 29, 4508 (1996).

b) I. Capek, M. Riza, and M. Akashi, J. Polym. Sci., Part A: Polym. Chem., 35, 3131 (1997).

3. a) H. Bamnolker and S. Margel, J. Polym. Sci., Part A: Polym. Chem., 34, 1857 (1996).

b) A. J. Paine, W. Luymes, and J. McNulty, Macromolecules, 23, 3104 (1990).

c) C. M. Tseng, Y. Y. Lu, M. S. El-Aasser, and J. W. Vanderhoff, J. Polym. Sci., Part A: Polym. Chem., 24, 2995 (1986).

4. H. Uyama and S. Kobayashi, Polym. Int., 34, 339 (1994).

5. a) Y. Chen and H. Yang, J. Polym. Sci., Part A: Polym. Chem., 30, 2765 (1992).

b) K. P. Lok and C. K. Ober, Can. J. Chem., 63, 209 (1985).

c) A. J. Paine, J. Colloid Interface Sci., 138, 157 (1990).
6. a) A. Tuncel, R. Kahraman, and E. Piskin, J. Appl. Polym. Sci., 50, 303 (1993).

b) T. Corner, Colloids Surf., 3, 119 (1981).

7. "Progress in Polyimide Chemistry I (Advances in Polymer Science, Vol. 140)," H. R. Kricheldorf, Ed., Springer Verlag, Berlin, 1999.

8. W. Volksen, in "High Performance Polymers (Advances in Polymer Science, Vol. 117)," P. M. Hergenrother, Ed., Springer-Verkag, Berlin, 1994, p 111.

9. S. Watanabe, K. Ueno, K. Kudoh, M. Murata, and Y. Masuda, Macromol. Rapid Commun., 21, 1323 (2000).

10. a) S. Kobayashi, H. Uyama, S. W. Lee, and Y. Matsumoto, J. Polym. Sci., Part A: Polym. Chem., 31, 3133 (1993).

b) P. Lacroix-Desmazes and A. Guyot, Polym. Adv. Technol., 8, 608 (1997).

11. a) E. Bourgeat-Lami and A. Guyot, Polym. Bull., 35, 691 (1995).

b) E. Bourgeat-Lami and A. Guyot, Colloid Polym. Sci., 275, 716 (1997).

12. S. R. Sandler and W. Karo, "Polymer Syntheses" Academic Press, Inc., San Diego, CA, 1992, pp 257-265.

13. G. D. Jones and S. J. Goetz, J. Polym. Sci., 25, 201 (1957).

14. R. Belcher, M. A. Leonard, and T. S. West, J. Chem. Soc., 2390 (1958).

15. In the previous paper, the effect of VBA/2a molar ratio was studied. The equimolar amount of VBA to the carboxylic acid of $\mathbf{2 a}$ i.e., $\mathrm{VBA} / \mathbf{2 a}=2$, was optimum to afford the PAA immobilized particles in quantitative yield. ${ }^{9}$ In this article, the molar ratio of VBA to $2 \mathbf{a}$ was fixed at 2.4. 